\title{
MAPEAMENTO DE RISCO: ANÁLISE SITUACIONAL DA BIBLIOTECA CENTRAL DA UNIVERSIDADE FEDERAL DA PARAÍBA
}

\author{
Victor Luiz Campos da Costa \\ Orientando \\ admhtkd@hotmail.com \\ Marynice de Medeiros Matos Matos \\ Prof ${ }^{a}$ Doutora - DCI-PPGCI-UFPB \\ Orientadora \\ mrynice.autran@gmail.com
}

Resumo

Este estudo propõe discutir algumas causas e resultados dos riscos de acidentes de trabalho, bem como identificar a percepção dos Gestores da Biblioteca Central do Campus I da Universidade Federal da Paraíba quanto a esses riscos em seu local de trabalho, colocados graficamente através do mapeamento de riscos sugeridos pela legislação vigente. A pesquisa desenvolvida pode ser caracterizada pela sua tipologia como analítica, e para tanto, foram coletados dados a partir de bibliografias referentes à normas e leis de segurança de trabalho, tendo como fontes o Ministério do Trabalho, Ministério da Saúde e Ministério da Previdência e Assistência Social, e estudiosos do tema. Foram também aplicadas entrevistas por meio de questionários, aos gestores da Biblioteca avaliada. Identifica-se a partir dos resultados obtidos que, por parte dos gestores ainda faltam maiores esclarecimentos em relação ao tema, e principalmente a questão da cultura da prevenção. Verifica-se ainda que, as causas dos acidentes encontrados, são diversas: o desconhecimento e/ou avaliação ineficaz do risco, baixo investimento de prevenção, ausência de treinamento e falta ou não-uso dos EPI (Equipamentos de Proteção Individual) e falhas estruturais do prédio. É evidente que, o processo de segurança na biblioteca avaliada, deve partir desde o planejamento até a operacionalização de suas atividades, bem como da instauração de Programas e Comissões, direcionados à segurança, conforme a Legislação vigente. Com isso, a conscientização a respeito das práticas de segurança por parte de todos os componentes da organização, deve ser preconizada.

Palavras-chave: Medicina e Segurança do Trabalho, Mapa de Riscos, Biblioteca Universitária. 